\title{
Mergers in European Higher Education Financial Issues and Multiple Rationales
}

\author{
Rocha, Vera; Teixeira, Pedro N.; Biscaia, Ricardo
}

Document Version

Accepted author manuscript

Published in:

Higher Education Policy

DOI:

10.1057/s41307-017-0076-2

Publication date:

2019

License

Unspecified

Citation for published version (APA):

Rocha, V., Teixeira, P. N., \& Biscaia, R. (2019). Mergers in European Higher Education: Financial Issues and Multiple Rationales. Higher Education Policy, 32(2), 185-202. https://doi.org/10.1057/s41307-017-0076-2

Link to publication in CBS Research Portal

\section{General rights}

Copyright and moral rights for the publications made accessible in the public portal are retained by the authors and/or other copyright owners and it is a condition of accessing publications that users recognise and abide by the legal requirements associated with these rights.

Take down policy

If you believe that this document breaches copyright please contact us (research.lib@cbs.dk) providing details, and we will remove access to the work immediately and investigate your claim. 


\title{
Mergers in European Higher Education: Financial Issues and Multiple Rationales
}

\author{
Vera Rocha, Pedro N. Teixeira, and Ricardo Biscaia
}

Journal article (Accepted version*)

\section{Please cite this article as:}

Rocha, V., Teixeira, P. N., \& Biscaia, R. (2019). Mergers in European Higher Education: Financial Issues and Multiple Rationales. Higher Education Policy, 3А2), 185-202. https://doi.org/10.1057/s41307-017-0076-2

This is a post-peer-review, pre-copyedit version of an article published in Higher Education Policy. The final authenticated version is available online at:

DOI: https://doi.org/10.1057/s41307-017-0076-2

* This version of the article has been accepted for publication and undergone full peer review but has not been through the copyediting, typesetting, pagination and proofreading process, which may lead to differences between this version and the publisher's final version AKA Version of Record.

Uploaded to CBS Research Portal: August 2019 


\section{Mergers in European Higher Education: Financial Issues and Multiple Rationales}

\section{Introduction}

The pace of change in Higher Education (HE) sector has been accelerating in many countries due to a multitude of complex and interacting forces (Clotfelter, 2010; Shattock, 2008). Continuing constraints on public funding (Barr, 2004), which have been exacerbated under the recent global economic crisis, have placed great pressure upon governments towards reforms aiming at improving the effectiveness and efficiency of HE systems (Jongbloed et al, 2010). With public and institutional budgets under pressure, there has been a renewed interest in exploring mergers and institutional consortia that could be effective in reducing higher education institutions' (HEIs) rising costs (Clotfelter, 1996; Archibald and Feldman, 2010; HEFCE, 2012) and lighten the burden of public budgets. Moreover, combining central services, material and human resources, was seen as a possible opportunity for scale economies that could free resources for fundamental missions, such as teaching and research (Matthews, 2013).

The widespread concerns about HEIs' competitiveness, research quality, and international reputation have been reinforcing the belief that size matters in higher education. Larger institutions are believed to have the potential for more concentrated firepower, cross-fertilization, and greater diversity. Thus, high expectations regarding cost efficiency, economies of scale and scope, and brand leverage were among the main motivations of a number of recent merger processes around the world in HE (e.g., Rowley, 1997a, 1997b; Skodvin, 1999; Eastman and Lang, 2001; Curri, 2002; Kyvik, 2002; Harman and Harman, 2003; Wan and Peterson, 2007; Kyvik and Stensaker, 2013).

Although a significant body of the HE literature has addressed the issue of mergers, most research has so far followed a case-study approach and has not presented yet a broader perspective on waves of mergers in the higher education sector. Furthermore, 
very little comparative work has been done, trying to identify common patterns and developments across different European systems. Furthermore, management literature has hitherto privileged the analysis of the business sector, which contrasts with the notfor-profit status of nearly all universities and colleges of tertiary education. Altogether, we still know little about the subject and very few studies have tried to go beyond the descriptions of localized cases and to look at the existing processes from an international comparative approach that may help to identify patterns and peculiarities, as well as major policy and institutional issues from recent experiences.

In this paper, we analyze the European experience with mergers in higher education in recent years. We map the main processes of HE mergers and consortia that occurred in 25 European countries since the early 2000s. In the next section, we discuss the policy and institutional context that has been framing the recent wave of higher education mergers in Europe. In Section 3, we describe the scope of our study and map the existing processes of HE mergers in Europe, aiming at identifying the main differences and similarities between the experiences of the 25 countries. The analysis mostly focuses on the extent to which mergers have been recently observed in national HE systems, the type of HEIs involved, and the role played by public authorities. Section 4 characterizes in more detail those HE mergers and collaboration agreements, namely regarding the main drivers and motivations underlying these processes, and the key difficulties encountered during the reorganization of the systems. We acknowledge that the main impacts and possible economic gains that might have resulted from mergers in each HE system are still difficult to evaluate, given the long timespan required for the whole process to be completed. Therefore, section 5 concludes and leaves several questions about the efficacy of HE mergers open for future research, yet providing some reflection and policy implications regarding the link between merger processes in higher education and both research policy and funding strategies.

\section{Higher Education Mergers in Europe: Policy and Institutional Context}

As in many other public services, the pressure to contain public expenditure became rather common in higher education over the recent years (Barr, 2004; Johnstone and Marcucci 2010). This has led to multiple attempts to improve the efficiency of public 
HE systems and to devise ways to make HEIs more efficient in the use of (public) resources (Pollitt and Bouckaert 2011). These rising concerns with efficiency have had a clear impact in the relationship between HEIs and governments, which has been visible in changes in the regulatory framework of public higher education in Europe, notably as regards funding (e.g., Chevaillier and Eicher 2002; Liefner 2003). Underpinning these changes has been the goal of policy-makers to promote greater institutional and systemic efficiency, namely by enhancing competitive stimuli within the system (Docampo 2007).

One of the instruments considered in this respect in recent years has been the possibility of achieving scale and scope economies through the unification of two or more HEIs. As a result, mergers have become a more common phenomenon in many systems. Motivated by strong expectations on successful outcomes regarding cost efficiency, economies of scale and scope, as well as brand leverage, numerous restructuring processes have been initiated by national governments, or by institutions themselves, to achieve a variety of purposes. Problems of institutional fragmentation, lack of financial and academic viability, low efficiency and quality, and several external threats related with demographic changes and competition have often been at the origin of major reorganization processes of that type (Rowley, 1997a, 1997b; Eastman and Lang, 2001; Curri, 2002). This has included a wider spectrum of institutions in the HE sector, including non-university research institutes and private HEIs.

Several universities of different size and reputation have decided to relinquish their institutional independence in exchange of the perceived advantages that may come with being subsumed into a larger institution - either due to government pressures or in a more voluntary (and strategic) way (Goedegebuure, 2012; Kyvik and Stensaker, 2013). National experiences with HE mergers are noticeable around the globe. Outside Europe, there are several cases of mergers in HE sector in Australia, Canada, China, South Africa and the United States. ${ }^{1}$ In Europe, the first major wave of HE mergers appeared during the 1980s and early 1990s, namely in the UK (Rowley, 1997a; 1997b), The Netherlands (Goedegebuure, 1992), and Norway (Norgard and Skodvin, 2002; Kyvik,

\footnotetext{
${ }^{1}$ See, for instance, Harman (1986), Goedegebuure (1992), Gamage (1993), Abbott (1996), Curri (2002) and Pick (2003) for Australia; Eastman and Lang (2001) for Canada; Huang (2000), Wan and Peterson (2007) and Mao et al. (2009) for China; Hay and Fourie (2002) and Sehoole (2005) for South Africa; Bates and Santerre (2000) and McGinnis et al. (2007) for US.
} 
2002; Kyvik and Stensaker, 2013), followed by a widespread merger trend across Europe since the early 2000 s.

At the policy level, there is often the assumption that mergers may provide significant benefits regarding savings and financial resources. In parallel, a surge of recent mergers in Europe - mostly policy-induced - had in several cases the ambitious goal of creating "world-class universities" (Goedegebuure, 2012), which are believed to be able to compete at the top-end of international markets for prestige, staff, and students. Increasing the level of integration is actually one of the most prominent policy objectives for research in Europe (Luukkonen and Nedeva, 2010), featuring the agendas for higher education of European Programs such as the Horizon 2020, so identifying the mechanisms leading to the desired level of integration in research is part of this policy process. As a result, mergers, federations, alliances, and strategic collaborations between HEIs have become a pivotal policy instrument, not only to stimulate the system, but also to deal with its deficiencies and inefficiencies.

The interest in mergers and consortia has also been fostered by some important developments at the European and international levels. In recent years, we have observed important forces promoting the development of an increasingly integrated European higher education landscape, which has been shaped by a reconfiguration of the sector alongside market rules, often through policy initiatives and government intervention. Although Europe has traditionally had a more egalitarian approach towards higher education, this has gradually become less the case over time. In recent years, we have seen a greater willingness of European policies towards the concentration of resources and talent in a few regions and institutions (Teixeira, 2013). The growing relevance of European research funding has furthermore encouraged both the strengthening of national competitors and the establishment of partnerships and alliances between like-minded actors. We thus observe several governments across Europe strengthening a few of their institutions (e.g. the excellence initiatives in Germany or France), or encouraging mergers that might lead to stronger competitors in the future.

Even though financial factors have been underlying most of the recent mergers, these restructuration processes have also been associated with other multiple motivations. Moreover, some of these latest experiences suggest that cost reduction may be 
misleading as the primary impetus for a merger. Existing evidence provides ambiguous support for the assumption of economies of scale in large HEIs, given that size typically has opposing effects on the expenditure level (see, for instance, Brinkman and Leslie (1986), Cohn et al. (1989) and Kyvik (2002)). Furthermore, merger costs and risks are often underestimated, frequently requiring more effort, time, and money than usually expected. Besides, the lack of publicly available information so far, in the form of postmerger evaluation reports or other analyses of outcomes that might show the impact of mergers in HE sectors, still averts the evaluation of the efficacy of mergers in improving HEIs' competitiveness and efficiency.

We need to deepen our knowledge of those managerial and organizational factors, in order to understand the possibilities and limitations faced by many institutions and the potential impact of the current wave of policies promoting mergers in re-shaping the higher education landscape, particularly in Europe. In the following section, we analyze these issues by looking at merger processes that took place in various European higher education systems in recent years, by mapping the multiple motivations associated with that wave, including the financial ones.

\section{Mapping existing HE merger processes in Europe}

In the framework of the DEFINE Project (Designing Strategies for Efficient Funding in Higher Education in Europe), we have analyzed the merger experiences in the HE sector of 25 European countries since the early $2000 \mathrm{~s}^{2}$ The analysis was primarily based on the responses obtained from the National Conferences of Rectors (NRCs) of the 25 countries to a survey implemented in late 2012, and complemented with "grey literature" (namely technical reports from government agencies and scientific reports from previous projects on this subject) and scientific literature on the topic (namely journal articles and books on particular merger experiences). A second round of

\footnotetext{
${ }^{2}$ The 25 countries covered in our analysis are the following: AT - Austria; BE-fr - Belgium (French Community); BE-fl - Belgium (Flemish Community); HR - Croatia; HU - Hungary; CZ - Czech Republic; DE - Germany; DK - Denmark; EE - Estonia; FI - Finland; FR - France; GR - Greece; IE Ireland; IT - Italy; IS - Iceland; LV - Latvia; LT - Lithuania; NL - Netherlands; NO - Norway; PL Poland; PT - Portugal; SK - Slovakia; ES - Spain; SE - Sweden; TR - Turkey; UK - United Kingdom. For more details on the DEFINE project, please refer to the official webpage: http://www.eua.be/define.
} 
questions was sent to the same NRCs by the second half of 2013, in order to clarify some of the aspects and the data collected in the first round.

The audience chosen for the survey related to our purpose to map existing processes and to gather an overview rather than focusing on the specific aspects of individual mergers. By addressing national rectors' organizations we are not only gathering information about systemic developments, but also the institutional perspectives, namely regarding the potential differentiation that those mergers processes may entail. To a certain extent, this is a fruitful level to be explored, as it combines elements of systemic overview with institutional concerns and motivations. It also poses some limitations, as we tend to gather more limited knowledge about specific experiences and developments, since their views tend to focus on patterns and major trends. This limitation was partially mitigated in a second stage in 2014, when we have addressed a focus group with representatives from 19 institutions (11 countries) that have undergone merger processes in several European countries. This has helped to complement, clarify, and nuance the views expressed in the survey by the NRCs representatives.

With this study we aimed at analyzing the following elements in each HE system, in order to provide a broader overview of the recent wave of merger processes in European HE: i) whether or not a recent trend towards mergers or other concentration and collaboration processes has taken place in the several HE systems; ii) whether any identifiable pattern could be found regarding the type of institutions involved; iii) the role played by public authorities in those processes; iv) the main motivations and drivers leading to those merger experiences; v) the importance of financial incentives and funding motivations; vi) and, whenever possible, the feedback from the sector. In the remainder of the text we present the main results and conclusions from this study. In this section we cover the first three issues. The other three are addressed in the next section.

\subsection{Identifying recent trends towards mergers in European HE}

According to the responses provided by the NRCs, mergers/federations or other types of collaboration processes have taken place or were being discussed in all countries analyzed (excluding Turkey) by the time of our survey. Nevertheless, different stages 
were observed in each country, namely in terms of the number of institutions involved, their relevance in relation to the size of the system, and the types of HEIs engaged in those mergers. According to Table 1, the most frequent case corresponded to the fullyfledged merger of two or more universities into a new entity. The integration of a smaller institution (or independent faculty) into an already existing institution was also often observed. Merger processes occurred both among the same sort of institutions and between different types of HEIs (e.g., universities and non-university research institutes; universities and vocational college; research centers).

Out of the 25 countries under analysis, such developments have been observed in nine systems (Belgium, Denmark, Estonia, Finland, France, Hungary, Latvia, Norway, and Sweden), even though it was a very recent trend in some countries. ${ }^{3}$ In seven other systems (Austria, Croatia, Iceland, Poland, Lithuania, Slovakia, and UK), mergers or institutional consortia have manifested to a more limited extent, targeting a relatively smaller share of institutions. In five other higher education systems (Czech Republic, Greece, Italy, Ireland, and Portugal) the discussions about mergers had just started and their impact was, therefore, still limited. ${ }^{4}$

\section{Insert Table 1 here}

By contrast, in three countries HE mergers had been rare or non-existent. No mergers occurred during the last decade in Spain nor in The Netherlands, while in Germany the history of mergers is still considered to be very singular. In these countries, there has been rather a tendency to intensify collaboration between institutions (e.g., on research), without requiring any mergers or incorporations among HEIs. Actually, even in those systems where mergers are becoming a trend, we also observe an increasing creation of federations, consortia, and strategic alliances among HEIs, in order to cooperate in a

\footnotetext{
${ }^{3}$ It is rather noteworthy that several of those countries are located in the Northern part of the Continent, with a tradition of strong regulation and a visible role of public policy in higher education. At the same time, these are countries with a limited presence in leading positions in international rankings of HEIs, which may have strengthened the motivations linked to international visibility, reputation, and attractiveness (more on this below).

${ }^{4}$ For Portugal in particular, though no trend towards mergers was explicitly assumed to exist according to the NRCs, there were a number of mergers in the period 2004-2007, mainly involving small vocationallyoriented public HEIs and/or small private institutions.
} 
number of activities, though not necessarily considering a complete merger (see Table 2). Finally, in Turkey, developments have gone in the opposite direction, with the creation of new HEIs, thus expanding rather than consolidating the system, due to the increasing enrolments and the growing demand for HE in the country.

\section{Insert Table 2 here}

Differences are also observed regarding the timing of these mergers. In Eastern Europe these processes have become rather visible, following the major political transformations of the early 1990s. A few mergers have been completed in Poland since the late 1990s and a few more were under consideration by the time of our survey, though this may still be considered a small-scale phenomenon given the high number of HEIs in the system (about 450). Both Croatia and Slovakia reported internal institutional concentration and consolidation processes such as the merger between (and thus dissolution of) faculties, dating back to mid-1990s and 2002, respectively. Croatia in particular has entailed such restructuration in $\mathrm{HE}$ to overcome the traditional fragmentation of the system, leading to three fully-fledged mergers between 2002 and 2006. In Slovakia, in turn, one merger was completed by 2005. In Hungary, merging processes started around 2000 and, meanwhile, the initial number of 50 universities became 28 after the integration wave.

Mergers have also been a topic of debate in higher education policy in Nordic and Baltic countries. In Finland and Sweden, the discussions and preparations had been going on for about a decade, with several mergers taking place during recent years and some more being on the way, though with some specific differences in other systemic aspects relevant to those processes (such as the evolution of the levels of public funding or the spatial dispersion of HEIs and campuses). Since 2003/04, mergers and dissolutions in the Estonian HE system resulted in a decrease of about $60 \%$ in the number of HEIs. In Denmark, several mergers were entailed in 2007, followed by Iceland with a merger in 2008, and Norway with the implementation process starting in 2009. More recently, merging processes also started in Latvia (2009-2011) and in Lithuania (2010-2011). 
In Western and Southern Europe, there have been also some movements towards greater collaboration and consortia between institutions. In Belgium, a closer cooperation between HEIs has been achieved since 2004 through both the creation of Academies (which gather several universities) and some university mergers. In Germany, in contrast, only two mergers took place in 2005/2006, while the opposite pattern occurred among universities of applied sciences, which have split into new institutions. Closer cooperation among institutions and non-university research centers has been fostered by the federal government's excellence initiatives. In Austria, the trend started around $2009 / 2010$, with a number of non-university research centers being attached to universities. This model of increasing collaboration was also observed in France since 2006, owing to the establishment of a new legal framework for HE and research clusters (PRES - Research and Higher Education Clusters). Such development has also been further encouraged since 2009 by the government's excellence initiative, with some mergers having been documented within these clusters. Finally, in Southern Europe there were a few examples of mergers in Italy (2010) and Portugal (with one merger approved in 2012). In Spain, no mergers had taken place, but signs of closer cooperation were observed since 2008, owing to the government's initiative of "campuses of excellence" composed by several institutions.

\subsection{The role of public authorities}

Regarding the role of governments in promoting those processes, several respondents indicated that the policy context had been somewhat favorable to mergers and concentration processes. However, the extent to which public authorities and policymakers tried to foster and/or steer the process varied, as well as the degree of collaboration between institutions and public authorities. Figure 1 summarizes the relative position of each national system regarding the relative extensiveness of mergers within each HE system and the role that public authorities had been playing in those processes (taking into account the responses obtained from NRCs in the first round, subsequent validations in the second round, and the feedback collected from the focus group).

The overall picture suggests that, in several systems, the general discussions about the topic of mergers seem to have been initiated by policy-makers (e.g., Greece, Hungary, 
Latvia, and Slovakia). In some systems (for instance, in Latvia), some mergers occurred even without much discussion with the sector. In other countries, most of the mergers (either completed or ongoing) were voluntarily initiated by the institutions themselves (e.g., Norway, Poland, Portugal, Sweden, and UK), though often additionally encouraged by the government (for instance, through additional funding).

In other cases, a joint approach seems to have been chosen, with the processes being implemented through the joint initiative of public authorities and institutions. In Belgium and France, though the pressure for mergers came from public authorities, the actual processes and decisions were taken by institutions with some degree of autonomy. Similarly, in Denmark, mergers took place after some political pressure upon institutions, but universities had a major initiative in the process. In Estonia, most processes were initiated by HEIs, yet those individual decisions had been encouraged by several changes in the HE sector, namely those related to the accreditation system. In Finland, mergers were perceived as an outcome of a nationwide structural development, though the universities involved had kept their autonomy during the process.

\section{Insert Figure 1 here}

Although several countries mention a rather combined approach where governments and individual HEIs both take the initiative towards restructuration, it is difficult to assess how the interaction between the two parts really worked in the different stages of the process (i.e., initiative, planning, and implementation). Different HE systems seem to exhibit different experiences, and even within a system different approaches might coexist. Likewise, the extent to which mergers are the preferred alternative to reorganize the system also seems to vary across Europe. For instance, in the case of Spain, collaboration agreements between institutions (namely at the research-level) had occurred on a voluntary basis, without any evidence of a willingness to merge. Similarly, in the Netherlands, universities and the government had been jointly exploring new opportunities for federations and cooperation between HEIs. 


\section{Characterizing existing processes in Europe: Drivers, Difficulties, and Results}

This mapping study foremost aims at contributing to existing research with a broader overview of the systemic and institutional challenges associated with HE merger processes, in order to understand the opportunities and limitations faced by many institutions, and the potential impact of the current wave of policies promoting mergers in European higher education. Thus, in this section, based on the responses to our survey, we analyze the main motivations and drivers leading to those merger experiences, the importance of financial incentives and funding motivations, and, as far as possible, the feedback from the sector regarding these recent initiatives.

\subsection{The role of financial incentives}

In most of the systems analyzed, there was often some type of financial incentive provided by public authorities to stimulate HEIs towards merging or establishing closer collaborations. In Belgium (French Community), additional funding was received by the new Academies resulting from the restructuration process, in order to support some initiatives, such as the award of $\mathrm{PhD}$ degrees. In Croatia, financial incentives had been provided though tuition fees subsidies. In Czech Republic, the only merger completed by the time of the survey had been supported by a government-funded project, and in Lithuania considerable financial support had been provided to sustain similar processes. In Poland, special financial incentives had been proposed, such as the guarantee of additional funding in the three years following the merger. Similarly, in Sweden, seed funding and other types of financial encouragement (e.g., promises of additional research funding) were also used by the government to stimulate merger processes among HEIs.

In several other systems where funding schemes had been implemented to foster HEIs' excellence, financial incentives had also stimulated a closer cooperation between institutions, mainly in research (e.g., Spain, Germany, and France). In the Netherlands, a stronger cooperation in the form of strategic alliances was assumed to be one of the goals included in the performance agreements between public authorities and universities, and for that purpose financial incentives had played a significant role. In 
other systems, there seemed to be no specific financial incentives ex-ante, though they could be present indirectly, as in the cases of Denmark, Estonia, or Latvia.

\subsection{Other drivers and motivations for mergers and collaborations}

Our results indicate more than one motive or objective for mergers and collaboration processes, though it is difficult to distinguish between system- and institutional-level drivers. Table 3 provides a summary of the main drivers identified by the HE systems under analysis. The main motivations reported can be summarized into four categories: 1) Economic gains; 2) Enhancement of HEIs' relative position; 3) Quality Improvement and 4) Consolidation of the system. Economic gains were reported by more than half of the systems and include cost reductions, increased efficiency, and even survival reasons. One may argue that expectations of significant economies of scale, which could be attained by creating larger and stronger institutions, were frequently underpinning many of these restructuring processes.

\section{Insert Table 3 here}

Besides those "necessity-driven" processes, a number of strategic motivations were also identified. The enhancement of the institutions' relative position through increased regional, national and/or international competitiveness, which, in turn, was also expected to improve the HEIs' relative position with the several stakeholders, was mentioned as a motivating force in the merger processes of ten countries. Objectives of

quality improvement, both in teaching and research, were also mentioned by a remarkable number of respondents. The strengthening of collaborations and synergies between universities and non-university institutions was also frequently mentioned as an objective to accomplish in the short/medium term, in order to make the overall $\mathrm{HE}$ system much more compact and consistent. 
Finally, the need to consolidate the network of HEIs was also generally recognized as a common driver of mergers, integrations, and collaboration agreements in HE sector. The demographic decline or the excessive fragmentation of some systems prompted an increasing need to eradicate duplicated programs. Thus, the objective of creating critical mass was mentioned by several countries (e.g., Portugal, Sweden, Denmark).

In summary, both positive motivations (e.g., the willingness to combine the strengths of two or more HEIs) and more negative drivers (e.g., HEIs' financial troubles) seem to have motivated most merger experiences. Consequently, different results may be also obtained according to the diverse motivations leading to this type of reorganization among HEIs. In fact, the success of such processes may be, at least in part, explained by the reasons behind their origin, as national experiences apparently suggest.

\subsection{Overall feedback, main outcomes, and challenges}

In our survey we tried to gather the perceptions among national institutional organizations about the recent mergers and collaboration processes. The feedback collected was rather positive in the cases of Croatia, Finland, Czech Republic, and France, but somewhat negative in Austria and Latvia. In some systems the feedback was mixed - e.g., in UK, the feedback had been positive for voluntary mergers, but negative for policy-induced ones. Nevertheless, some benefits were already identified. These included the development of more efficient centralized services (Croatia), profiling and strengthening of centers of knowledge (Finland), stronger and more comprehensive institutions (Finland, France and Poland), greater proximity, collaboration, and networking between institutions (France and Iceland), and enhanced quality of both education and research (Finland and Poland).

Regarding the main challenges and difficulties reported by the respondents, the main challenge reported was the integration of different institutional cultures and the creation of a common/new identity (Denmark, Estonia, Finland, France, Lithuania, and Sweden), followed by the establishment and acceptance of new structures (Estonia, Norway, and Sweden), and the resistance among staff members (Croatia and Poland). Additional challenges included those related with the material and financial pre-existing structures, such as the need for new investment into infrastructures (Austria), and the need to deal 
with the remaining infrastructure of the old institutions (Hungary). Other obstacles referred to the decrease in funding in some cases (Finland), or the need to cope with geographical distances of the involved institutions (Sweden).

Our survey also intended to gather (sometimes preliminary) perceptions about the impact of mergers and collaborations, especially on financial issues. Most of the countries indeed recognized that it was too early to talk about benefits and outcomes from the restructuration suffered in their HE systems, especially in what concerned the potential effects on HEIs' financial position. Moreover, the lack of publicly available information - in the form of post-merger evaluation reports or other analyses of outcomes - that might show the impact of mergers and collaborations in the HE sectors does not allow, for now, any definitive conclusion regarding how effective have been mergers and consolidation processes in Europe, especially regarding funding issues.

The insights derived from other past experiences suggests that it may be difficult to attribute cost savings to institutional mergers due to the vast investments in resources and the long timespan often needed to actually consolidate that process (Harman and Meek, 2002; Pick, 2003; Goedegebuure, 2012). Therefore, the assumption that mergers make HEIs more capable to attract funds from sources other than governments' budgets (as long as restructuration processes improve their position and strengths, for instance, in research) is not yet possible to validate nor to refute. Many responses did confirm that it was too early to assess the overall process (e.g., Germany, Portugal, Greece, Italy, Latvia, and Lithuania), or that no general conclusions could be drawn from the overall system, since each case was regarded as different (as in Denmark). Based on other international experiences, we may expect that it can take up to ten years for the "wounds to heal and for the new institution forged from previously autonomous identities to operate as a cohesive and well integrated whole" (Harman and Meek, 2002: 4), thus explaining why it takes so long for many of the expected results to emerge. Hence, this is an aspect that requires subsequent monitoring and further research over the coming years.

\section{Concluding Remarks}


In recent years, there has been a visible wave of mergers in European higher education, which has been used by national governments and HEIs to achieve a variety of purposes. In this article, we have mapped and compared the main processes of $\mathrm{HE}$ mergers occurring in 25 European countries. Our analysis indicates that there are significant expectations being placed upon those processes, both by policy-makers and institutional actors. Current financial stringency has given additional visibility to these processes as a possible route to solve potential inefficiencies and funding problems in the sector. However, though many merger processes were motivated by financial pressures, other reasons have contributed to implement mergers and similar kinds of reorganizations in HE sector. A surge of recent mergers in Europe - mostly policyinduced - had the ambitious goal of creating world-class universities that could be able to compete internationally. With the growing international integration of higher education systems, competitive benchmarking has become a major influence in policymaking. As a result, mergers have become a pivotal policy instrument to stimulate the visibility and attractiveness of some institutions, notably by raising its size and its position in international rankings and league-tables.

The analysis also indicated that the recent wave presents similarities and nuances regarding previous waves of mergers in higher education. Thus, whereas some institutions consider mergers as a way to save money and share risks, especially in a period of significant austerity and uncertain student numbers, others have decided to enter a merger for more positive - often strategic - reasons. Stronger universities might look at mergers as a way to combine their strengths with other research intensive universities, to boost their research prowess, and to propel themselves further up in the international rankings. Actually, the latter factor seems to have gained relevance vis-àvis the financial ones, which has also contributed to change the profile of institutions involved. Whereas in the latter part of the twentieth century many mergers often took place among weak and less prestigious institutions, recent developments have involved more important and stronger players within national HE systems. This also indicates that different waves of mergers seem to be associated with some specific policy contexts and motivations.

The changes in the profile of actors and in their motivations are also relevant to explain a more hybrid situation regarding the steering of the process. Governments continue to play an important role, either directly or indirectly, but institutions seem to have 
attained a more significant role in recent mergers, several of which were the result of their own initiative. This is also likely to be explained by the fact that many European systems present several decades of strengthening institutional autonomy and their strategic capacity. HEIs are under rising pressure to compete and some of them are regarding mergers as a tool to strengthen their position in an increasingly challenging context.

Our analysis also indicates the relevance of managing the differences between the HEIs involved in a merger versus other type of collaborations. A "merger of equals" is rare and difficult to achieve. An effective collaboration necessarily comes from trust between the two (or more) parties, especially at the board level, and particularly during the negotiation and transition periods. Through a process recognized to be timeconsuming, requiring patience and persistence from all the members involved, the leadership of the partners has to create a new institution, a new identity, a new organizational fabric. If these processes are known to be clearly complex in a business environment, they seem to be even more so in the higher education sector. Universities are complex institutions that value significantly the role of their history, tradition, and norms, and those issues are particular relevant in a merger process. The aforementioned complexity is also reflected in the fact that the decision-making processes in many HEIs are based on formal and informal structures that involve (to variable degrees) each of the significant groups and interests in an attempt to build the largest compromise as possible for reaching decisions (Rosser, 2002). These dimensions suggest that the high expectations surrounding the current wave of merger processes need to be mitigated by the lessons learned from previous mergers and by the internal complexities of higher education institutions.

Overall, the analysis of the recent European experience with mergers indicates that these are increasingly regarded as a tool for "raising the bar", aiming at preparing HEIs for increased European and global competition (Clotfelter, 2010; Wildavsky, 2012). Given the persistent influence of competitive forces and benchmarking in higher education, this is likely to be strengthened as institutions and policy-makers regard them as instruments to improve their position in national and international rankings, and their attractiveness in the face of competitors. Moreover, the existing perceptions among institutional representatives indicate that mergers may deliver far less regarding financial savings and strategic positioning than some seem to expect. This should have 
implications for future research and for the development of national and institutional policies on this matter.

Our analysis indicates that we still have limited knowledge about the actual effects and impacts of those mergers at the system and institutional levels, and that more research needs to be done on this subject. We need to deepen our understanding about the potential, the implications, and the limitations of mergers in higher education, notably by taking into account not only the managerial and financial aspects, but also the organizational and academic dimensions. This requires that we bridge the gap between research on higher education and in management studies that may help improving our knowledge about such a fascinating and complex topic. This is not merely the standard claim in research, but a reflection of the multiple contexts, motivations, and processes associated with mergers in European higher education.

\section{References}

Archibald, R. B., Feldman, D. H. (2010), Why does college cost so much?, New York: Oxford University Press.

Barr, N. (2004), Economics of the Welfare State. $4^{\text {th }}$ ed, Oxford University Press.

Bates, L., Santerre, R. (2000), “A time series analysis of private college closures and mergers”, Review of Industrial Organization, 17(3), 267-276.

Brinkman, P.T., Leslie, L.L. (1986), "Economies of scale in higher education: sixty years of research", Review of Higher Education, 10(1), 1-28.

Clotfelter, C. (1996), Buying the Best - Cost Escalation in Higher Education, Princeton U Press; Princeton

Clotfelter, C. (Ed.) (2010), American Universities in a Global Market. Chicago: NBER and Chicago University Press.

Cohn, E., Rhine, S., Santos, M. (1989), "Institutions of higher education as multiproduct firms: economies of scale and scope, The Review of Economics and Statistics, 71(2), 284-290.

Curri, G. (2002), "Reality versus perception: Restructuring tertiary education and institutional organisational change - a case study", Higher Education, 44(1), 133151.

Eastman, J., Lang, D. (2001), Mergers in higher education - Lessons from theory and experience, Toronto: University of Toronto Press. 
Goedegebuure, L. (2012), "Mergers and More: The changing tertiary education landscape in the $21^{\text {st }}$ century", HEIK Working Paper Series, HEIKwp 2012/01, Faculty of Educational Sciences, University of Oslo.

Goedegebuure, L. C. J. (1992), Mergers in higher education - A comparative perspective, Management and Policy in Higher Education and CHEPS, Utrecht: Lemma.

Harman, G. (1986), "Restructuring higher education systems through institutional mergers: Australian experience, 1981-1983”, Higher Education, 15(6), 567-586.

Harman, G., Harman, K. (2003), "Institutional Mergers in Higher Education: Lessons from International Experience", Tertiary Education and Management, 9(1), 2944.

Harman, K., Meek, L. (2002), "Introduction to special issue: 'Merger revisited: international perspectives on mergers in higher education"', Higher Education, 44(1), 1-4.

Hay, D., Fourie, M. (2002), "Preparing the way for mergers in South African higher and further education institutions: An investigation into staff perceptions", Higher Education, 44(1), 115-131.

HEFCE (2012), "Collaborations, Alliances and Mergers in Higher Education. Consultation on Lessons Learned and Guidance for Institutions". September 2012/21, Higher Education Funding Council for England

Huang, H. (2000), "College and university mergers: impact on academic libraries in China", College \& Research Libraries, 61(2), 121-125.

Jongbloed, B., De Boer, H., Enders, J., and File, J. (2010) Progress in higher education reform across Europe Funding Reform. Brussels: DG for Education and Culture, European Commission.

Kyvik, S. (2002), "The merger of non-university colleges in Norway", Higher Education, 44(1), 53-72.

Kyvik, S., Stensaker, B. (2013), "Factors affecting the decision to merge: The case of strategic mergers in Norwegian higher education", Tertiary Education and Management, 19(4), 323-337.

Luukkonen, T., Nedeva, M. (2010), “Towards understanding integration in research and research policy”, Research Policy, 39(5), 674-686.

Mao, Y., Du, Y., Liu, J. (2009), "The effects of university mergers in China since 1990s - From the perspective of knowledge production", International Journal of Educational Management, 23(1), 19-33.

Matthews, D. (2013), "Meetings of minds or shotgun weddings?", Times Higher Education, 2084, January, 34-39. 
McGinnis, R., McMillen, W., Gold, J. (2007), "Merging two universities: The Medical University of Ohio and the University of Toledo", Academic Medicine, 82(12), 1187-1195.

Norgard, J., Skodvin, O. (2002), "The importance of geography and culture in mergers: A Norwegian institutional case study", Higher Education, 44(1), 73-90.

Patterson, G. (2000), "Findings on economies of scale in higher education: implications for strategies or merger and alliance", Tertiary Education and Management, 6(4), 259-269.

Pick, D. (2003), "Framing and frame shifting in a higher education merger", Tertiary Education Management, 9(4), 299-316.

Rosser, V. (2002), "Governance”, in J. Forest and K. Kinser (eds.), Higher education in the United States - An Encyclopedia, Santa Barbara (CA), ABC-CLIO, Vol. 1, pp. 279-284.

Rowley, G. (1997a), "United We Stand: A Strategic Analysis of Mergers in Higher Education", Public Money \& Management, 17(4), 7-12.

Rowley, G. (1997b), "Mergers in higher education: A strategic analysis", Higher Education Quarterly, 51(3), 251-263.

Sehoole, M. (2005), "The politics of mergers in higher education in South Africa", Higher Education, 50(1), 159-179.

Shattock, M. (ed.) (2008), Entrepreneurialism in Universities and the Knowledge Economy: Diversification and Organisational Change in European Higher Education. London: Open University Press

Skodvin, O. (1999), "Mergers in Higher Education - Success of Failure?", Tertiary Education and Management, 5(1), 65-80.

Teixeira, Pedro. (2013). The tortuous ways of the market: looking at the European integration of Higher Education from an economic perspective. LSE Policy Papers LEQS Paper No. 56/2013

Wan, Y., Peterson, M. (2007), "A case study of a merger in Chinese higher education: The motives, processes, and outcomes", International Journal of Educational Development, 27(6), 683-696.

Wildavsky, B. (2012), The Great Brain Race, Princeton University Press 
Table 1. Type of institutions involved in mergers, incorporations and collaboration agreements

\begin{tabular}{|c|c|}
\hline Type of Institutions & Countries \\
\hline Universities & $\begin{array}{l}\text { BE-fl; BE-fr; HR; HU; CZ; FI; FR; IS; LT; NL }{ }^{\mathrm{a}} \text {; PL; } \\
\text { PT; SE; UK }\end{array}$ \\
\hline $\begin{array}{l}\text { Non-university Research Institutes \& } \\
\text { Universities }\end{array}$ & BE-fl; AT; DE; DK; IE \\
\hline Private HEIs & EE; NO; PT \\
\hline Universities \& University Colleges & HR; HU; DK; EE ${ }^{\mathrm{b}}$; LV; NO; SK; UK \\
\hline Research Centers & HR; ES \\
\hline University Colleges & $\mathrm{DK} ; \mathrm{NO}$ \\
\hline Non-University Institutes & HR (libraries); DK \\
\hline
\end{tabular}


Table 2. Other types of collaboration processes besides fully-fledged mergers

\begin{tabular}{|c|c|c|c|c|c|c|}
\hline $\begin{array}{l}\text { Type of } \\
\text { Collaboration }\end{array}$ & $\begin{array}{l}\text { Financial } \\
\text { reasons }\end{array}$ & $\begin{array}{l}\text { Teaching/ } \\
\text { pedagogical } \\
\text { reasons }\end{array}$ & Research & $\begin{array}{l}\text { International } \\
\text { ization }\end{array}$ & $\begin{array}{l}\text { National } \\
\text { competition }\end{array}$ & $\begin{array}{l}\text { Regional } \\
\text { issues }\end{array}$ \\
\hline Consortia & $\begin{array}{l}\text { AT; BE-fr; FI; } \\
\text { IE; IT; LV; } \\
\text { NL; SE; }\end{array}$ & $\begin{array}{l}\text { BE-fr; FI; FR; } \\
\text { IE; IS; LT; } \\
\text { LV; }\end{array}$ & $\begin{array}{l}\text { BE-fl; BE-fr; } \\
\text { DE; FI; IE; IS; } \\
\text { IT; LT; LV; } \\
\text { PT; SE; }\end{array}$ & $\begin{array}{l}\text { BE-fl; FI; FR; } \\
\text { IE; IT; LT; } \\
\text { LV; SE; }\end{array}$ & $\begin{array}{l}\text { FI; FR; LT; } \\
\text { LV; NL; SE; }\end{array}$ & $\begin{array}{l}\text { FI; FR; IE; LT; } \\
\text { LV; NO; PT; }\end{array}$ \\
\hline Joint degrees & $\begin{array}{l}\text { BE-fl; DE; EE; } \\
\text { ES; LV; NL; } \\
\text { PT; }\end{array}$ & $\begin{array}{l}\text { AT; BE-fl; } \\
\text { BE-fr; EE; ES; } \\
\text { FR; IE; IS; IT; } \\
\text { LV; NL; NO; } \\
\text { PL; PT; SE; }\end{array}$ & $\begin{array}{l}\text { BE-fr; FR; IE; } \\
\text { IS; PL; }\end{array}$ & $\begin{array}{l}\text { AT; BE-fl; EE; } \\
\text { FR; IE; IT; } \\
\text { LV; NL; }\end{array}$ & EE; LV; NL; & FR; LV; NL; \\
\hline $\begin{array}{l}\text { Joint research } \\
\text { initiatives }\end{array}$ & $\begin{array}{l}\text { BE-fl; EE; FI; } \\
\text { IE; IT; LV; } \\
\text { NL; SE; }\end{array}$ & FI; LV; & $\begin{array}{l}\text { AT; BE-fl; BE- } \\
\text { fr; CZ; EE; ES; } \\
\text { FI; FR; IE; IT; } \\
\text { LV; NL; PT; } \\
\text { SE; }\end{array}$ & $\begin{array}{l}\text { AT; BE-fl; } \\
\text { BE-fr; DE; EE; } \\
\text { ES; FI; FR; IE; } \\
\text { IT; LV; PT; }\end{array}$ & $\begin{array}{l}\text { CZ; FI; IE; } \\
\text { LV; NL; NO; } \\
\text { PT; SE; }\end{array}$ & $\begin{array}{l}\text { CZ; EE; ES; } \\
\text { FI; FR; IE; } \\
\text { LV; NL; }\end{array}$ \\
\hline $\begin{array}{l}\text { Strategic } \\
\text { partnerships }\end{array}$ & $\begin{array}{l}\text { BE-fl;BE-fr; } \\
\text { DE; FI; FR; } \\
\text { IE; IT; LV; } \\
\text { NL; PL; }\end{array}$ & $\begin{array}{l}\text { BE-fl; BE-fr; } \\
\text { FI; FR; IE; } \\
\text { LV; PL; SE; }\end{array}$ & $\begin{array}{l}\text { BE-fl; BE-fr; } \\
\text { ES; FI; FR; IE; } \\
\text { IT; LV; NL; } \\
\text { PL; PT; SE; }\end{array}$ & $\begin{array}{l}\text { AT; BE-fl; } \\
\text { BE-fr; FI; FR; } \\
\text { IE; LV; NL; } \\
\text { PL; PT; }\end{array}$ & $\begin{array}{l}\text { FI; FR; IE; } \\
\text { LV; NL; }\end{array}$ & $\begin{array}{l}\text { AT; DE; FI; } \\
\text { FR; IE; IT; } \\
\text { LV; NL; PL; } \\
\text { SE; }\end{array}$ \\
\hline
\end{tabular}

Source: Own elaboration based on the responses of National Rectors. No significant information on these types of collaboration processes was obtained from $\mathrm{HU}, \mathrm{SK}, \mathrm{UK}$ and TR. 
Table 3. Summary of motivations and drivers for the mergers and collaborations in European Higher Education

\begin{tabular}{|c|c|c|}
\hline Category of Motivations & Examples of specific motivations & National responses \\
\hline Economic Gains & $\begin{array}{l}\text { Saving financial and human resources; } \\
\text { increasing efficiency; overcome } \\
\text { financial stringencies; survival reasons. }\end{array}$ & $\begin{array}{l}\text { AT; HR; HU; EE; FR; IS; LV; } \\
\text { LT; PL; SK; ES; SE; UK }\end{array}$ \\
\hline $\begin{array}{l}\text { Enhancement of HEIs, } \\
\text { relative position }\end{array}$ & $\begin{array}{l}\text { Increase the competitiveness at } \\
\text { regional, national and international } \\
\text { levels; strength the position in relation } \\
\text { to stakeholders (e.g., public authorities, } \\
\text { funders, company partners). }\end{array}$ & $\begin{array}{l}\text { CZ; DE; FI; FR; IS; NL; PL; PT; } \\
\text { SE; UK }\end{array}$ \\
\hline Quality Improvement & $\begin{array}{l}\text { Strengthen the research and teaching } \\
\text { quality; eliminate low quality } \\
\text { programs. }\end{array}$ & $\begin{array}{l}\text { HR; CZ; FI; IS; LV; NO; PL; } \\
\text { PT; UK }\end{array}$ \\
\hline Consolidation of the System & $\begin{array}{l}\text { Overcome the fragmentation and } \\
\text { duplication of programs, react to the } \\
\text { demographic decline; create critical } \\
\text { mass; foster collaborations and } \\
\text { synergies. }\end{array}$ & $\begin{array}{l}\text { BE-fr; HU; DE; DK; FR; LV; } \\
\text { PT; SE; UK }\end{array}$ \\
\hline
\end{tabular}

Source: Own elaboration based on the responses of National Rectors to the aforementioned questions regarding the main drivers and motivations for the mergers and collaboration processes. Turkey is not included in the Table above because this case is not applicable to the analysis (no history of mergers or collaborations). Italy is also excluded given that no reasons for mergers and collaborations were reported by National Rectors. In Greece, motivations are still under discussion and are not yet clearly defined. No information about the motivations of the mergers was received from Belgium (Flemish Community) and Ireland. 
Figure 1. Mapping merger processes and the role of public authorities in European Higher Education

$$
\begin{aligned}
& \text { Are these mergers/federations or other concentration processes } \\
& \text { being initiated by the public authorities, by the individual } \\
& \text { institutions themselves, by the sector or through a joint } \\
& \text { approach? }
\end{aligned}
$$

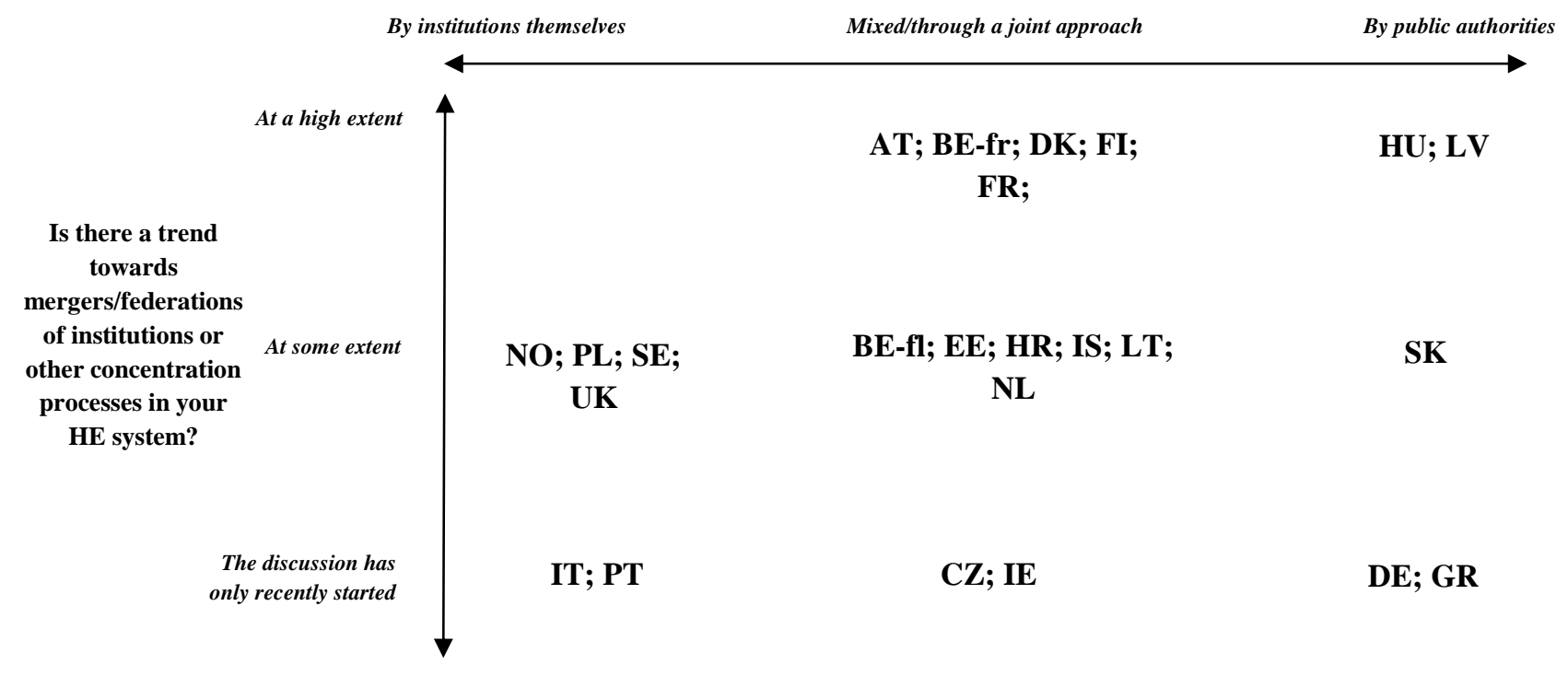

Source: Own elaboration based on the responses of National Rectors to the questions presented above. ES and TR are not included as no significant histories of mergers were found in these countries. 